\title{
Reducing Voltage Losses in the A-DAD-A Acceptor-Based Organic Solar Cells
}

Jun Yuan, Huotian Zhang, Rui Zhang, Yuming Wang, Jianhui Hou, Mario Leclerc, Xiaowei Zhan, Fei Huang, Feng Gao, Yingping Zou and Yongfang Li

The self-archived postprint version of this journal article is available at Linköping University Institutional Repository (DiVA):

http://urn.kb.se/resolve?urn=urn:nbn:se:liu:diva-170999

N.B.: When citing this work, cite the original publication.

Yuan, J., Zhang, H., Zhang, R., Wang, Y., Hou, J., Leclerc, M., Zhan, X., Huang, F., Gao, F., Zou, Y., Li, Y., (2020), Reducing Voltage Losses in the A-DAD-A Acceptor-Based Organic Solar Cells, CHEM, 6(9), 2147-2161. https://doi.org/10.1016/j.chempr.2020.08.003

Original publication available at:

https://doi.org/10.1016/j.chempr.2020.08.003

Copyright: Cell Press

http://www.cell.com/cellpress 


\title{
Reducing voltage losses in the A-DA'D-A acceptor-based organic solar cells
}

\author{
Jun Yuan, ${ }^{1,2}$ Huotian Zhang, ${ }^{2}$ Rui Zhang, ${ }^{2}$ Yuming Wang, ${ }^{2}$ Jianhui Hou, ${ }^{3}$ Mario Leclerc, ${ }^{4}$ Xiaowei Zhan, ${ }^{5}$ \\ Fei Huang, ${ }^{6}$ Feng Gao*2 Yingping Zou ${ }^{* 1}$ and Yongfang $L i^{3}$ \\ ${ }^{1}$ State Key Laboratory of Powder Metallurgy, College of Chemistry and Chemical Engineering, Central South \\ University, 410083 Changsha, P.R. China. \\ ${ }^{2}$ Biomolecular and Organic Electronics, IFM, Linköping University, 58183 Linköping, Sweden. \\ ${ }^{3}$ Institute of Chemistry, Chinese Academy of Sciences, Beijing, 100190, P.R. China. \\ ${ }^{4}$ Department of Chemistry, Universite Laval, Quebec City, Quebec G1V 0A6, Canada. \\ ${ }^{5}$ Department of Materials Science and Engineering, Peking University, Beijing 100871, China \\ ${ }^{6}$ Institute of Polymer Optoelectronic Materials and Devices, State Key Laboratory of Luminescent Materials and \\ Devices, South China University of Technology, Guangzhou 510640, P. R. China. \\ *Correspondence: feng.gao@liu.se (F.G.), yingpingzou@csu.edu.cn (Y. Z.)
}

Power conversion efficiencies (PCEs) of solution-processed organic solar cells (OSCs) have recently reached $17.4 \%$ (certified) for single-junction devices. Crucial to this advancement is the development of non-fullerene acceptors (NFAs) since 2015. The recent A-DA'D-A NFAs have attracted widespread attention because of their ladder-type electron-deficient-core-based central fused ring with improved transport properties and optimum energy levels. With the synergistic effect of electrondeficient-core and specific molecular geometry, the A-DA'D-A molecules could achieve low voltage losses and high current generation at the same time, reaching new regimes of device physics and photophysics. This perspective will discuss the voltage losses in state-of-the-art A-DA'D-A NFA-based OSCs, and propose new molecular design strategies to achieve PCEs over $20 \%$ in OSCs based on these new acceptors by further decreasing their total voltage losses.

\section{INTRODUCTION}

The demand for electricity has grown exponentially since the Industrial Revolution. ${ }^{1,2}$ In this regard, solar energy is renewable, environmentally friendly and abundant resource, and the use of solar cells to convert sunlight energy to electricity has rapidly increased. ${ }^{3-5}$ The first photovoltaic (PV) device was made around 1883. An important technological breakthrough was the development of the $p-n$ junction PV device based on silicon (Bell laboratories). ${ }^{6,7}$ After that the efforts for PV modules have spanned many different kinds of materials for PV devices, such as amorphous semiconductors, semiconducting thin films (such as cadmium telluride (CdTe) solar cells and copper indium gallium diselenide (CIGS) solar cells) as well as the conjugated organic materials for organic solar cells (OSCs), dye-sensitized solar cells (DSSCs)) and organic-inorganic metal halide perovskite solar cells. OSCs are a rapidly emerging PV technology in recent years, with the National Renewable Energy Laboratory (NREL) certified power conversion efficiency (PCE) rising from less than $1 \%$ to $17.4 \%$ (Figure 1a), ${ }^{7}$ encouraging initial lifetime $(>8,000$ hours unencapsulated, Figure $1 \mathrm{c})$, and potential for solution-processed roll-to-roll manufacturing at low temperatures. Moreover, the "zero energy concept" such as self-powered buildings and microelectronic industries (mobile devices, organic sensors and biomedical devices) may find OSCs especially attractive. ${ }^{8-10}$ This trend promotes research in the field of integrated PV markets, and in particular building integrated photovoltaics (BIPV) because of the availability of absorbers in several different colors and the ability to make efficient transparent devices. ${ }^{11-13}$ 
With regards to inorganic PV technology like Si or CIGS, free carriers are directly generated when a photon with sufficient energy strikes the $p$-n-junction, and the charges move via band transport. In organic material systems, photoexcited electron-hole pairs are, however, tightly bound. ${ }^{14}$ The strong coupling of the electron-hole (excitons) due to the low dielectric constant of organic materials, is causing the exciton binding energy an order of magnitude higher than the thermal energy at room temperature. Contemporary OSCS comprise an intermixed blend of electron donor (D) and acceptor (A) materials (bulk heterojunction (BHJ) structure), which in many material systems provides a fast and efficient route for exciton dissociation. ${ }^{15-17}$ As illustrated in Figure $1 \mathrm{~b}$, photons absorbed in either $D$ or A material create a singlet exciton $\left(S_{1}\right)$, and the excitons diffuse to the D/A interface where charge transfer (CT) results in the formation of CT excited state that can dissociate into holes on $D$ and electrons on A. Although the hole and electron are still subjected to Coulombic attraction and also can self-trap at the heterojunction, state-of-the-art OSC devices have peak external quantum efficiencies (EQE) over $80 \%$ and internal quantum efficiencies (IQE) over $90 \%{ }^{18-24}$ indicating very efficient separation of the CT states. Such a high quantum efficiency in organic materials, coupled with decent charge transport, makes it possible to deliver high short-circuit currents $\left(J_{\text {sc }}\right)$ and also high fill factor (FF) under one sun conditions.

This encouraging progress is mainly driven by the development of new photovoltaic materials, especially non-fullerene acceptor (NFA) materials in recent years. ${ }^{25-40}$ The quick development of NFAs is inspired by the materials design and synthetic methods developed during the past two decades for polymer donors in fullerene-based OSCs. State-of-the-art materials design involves a range of different aspects, including complementary absorption, suitable molecular orbital energy levels, high local mobility, molecular aggregation, dielectric constant, vibrational coherence, and molecular conformation etc. ${ }^{41-45}$ While marginal improvement of the $J_{\mathrm{sc}}$ and $\mathrm{FF}$ is possible by finely tuning the molecular structure, the open-circuit voltage $\left(V_{o c}\right)$ might be the only avenue for a further leap forward in device performance. ${ }^{46-48}$ In BHJ OSCs, charge separation is typically associated with large voltage losses because of the extra energy required to split excitons into free carriers. This voltage loss in state-of-the-art OSCs is usually around $0.6 \mathrm{~V}$, which is $0.2-0.3 \mathrm{~V}$ higher than that for c-Si and GaAs-based solar cells. ${ }^{49,50}$ So some of the key questions for the community to answer are: how to break the fetter of large voltage losses from a molecular design point of view? What type of molecular structures can lead to a new generation of materials with low voltage losses? In this Perspective, we discuss the relationships between open-circuit voltage, CT state properties and molecular characteristics, and also provide our understanding of design strategies for decreasing the voltage losses in high-performance NFA OSCs. 
(a)

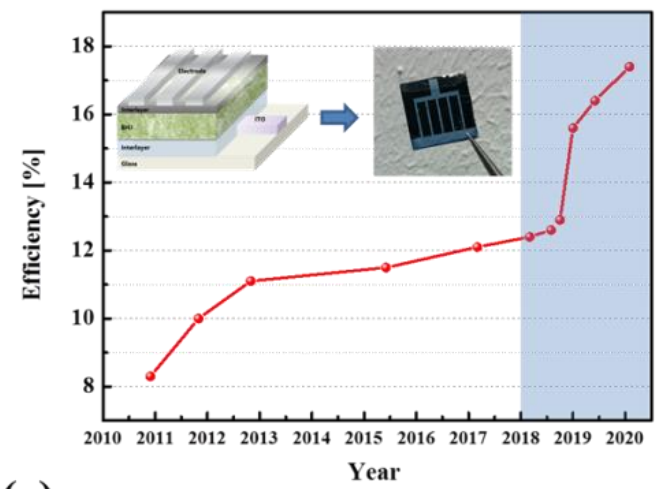

(b)

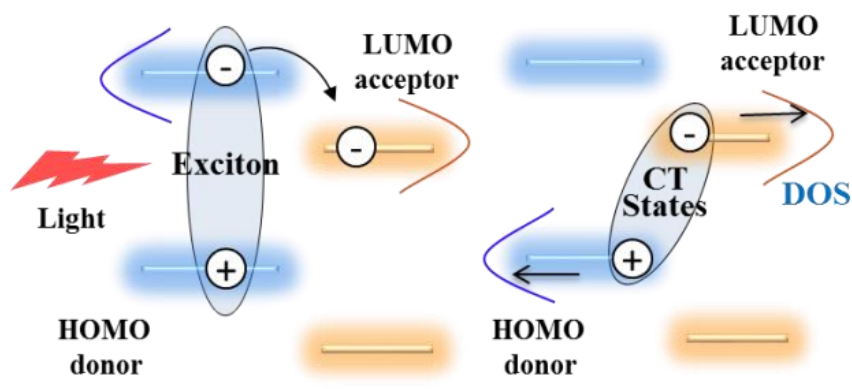

(c)
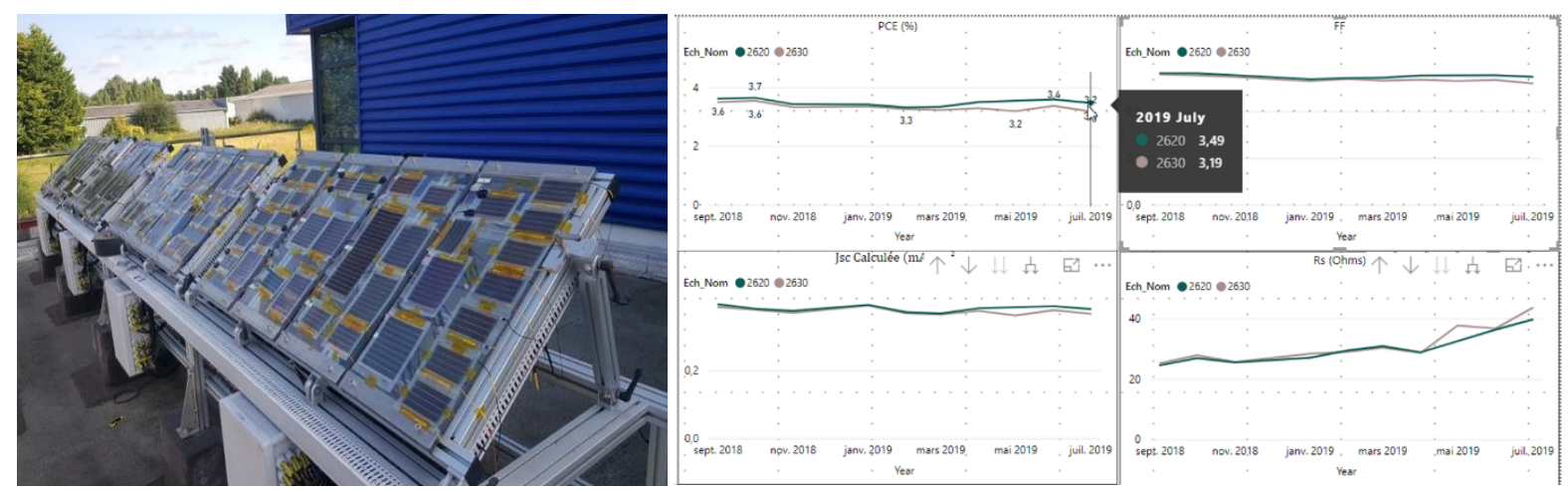

Figure 1. The power conversion efficiency and stability development of OSC technologies over the last decade.

(a) Data from NREL and Solar Cell Efficiency Tables (version 36-54) shows that the field of OSCs is experiencing a rapid process of development, especially from 2018 (the area of blue shading) with the development of A-DA'D-A type acceptors.

(b) The creation of CT-states across the donor-acceptor interface into their respective electrodes following photo-excitation: electrons via the LUMO levels in the acceptor, holes via the HOMO levels in the donor;

(c) Pictures provided by Armor Beautiful Light, outdoor aging of ASCA ${ }^{\circledR}$ OSC films.

\section{THE $V_{\text {oc }}$ AND VOLTAGE LOSSES IN ORGANIC SOLAR CELLS}

The $V_{\mathrm{oc}}$ in OSCs has been shown to strongly correlate with the energetic position of the CT state manifold, commonly referred to as the energy of the CT state $\left(E_{C T}\right)$ at the D/A interfaces, as well as recombination processes. In highly efficient devices developed during the past few years, the energy levels between the donor and acceptor are often aligned to enhance the $V_{\mathrm{oc}}$. In this case, the $E_{\mathrm{CT}}$ is very close to the singlet exciton energy of the narrow gap material in the blend.

Based on the principle of detailed balance and the assumption of quasi-equilibrium conditions, the $V_{\text {oc }}$ can correlate with externally measurable electro-optical spectra. This relationship can be written as the following equation:

$$
q V_{o c}=E_{g}-\left(E_{g}-q V_{O C}^{S Q}\right)-\left(q V_{O C}^{S Q}-q V_{O C}^{r a d}\right)+k T \ln \left(E Q E_{E L}\right)=E_{g}-\Delta E_{1}-\Delta E_{2}-\Delta E_{3}
$$

Here, $q$ is the elementary charge. $E_{g}$ is the optical gap of the solar cell device. The $q V_{O C}^{S Q}$ is the calculated maximum voltage based on the Shockley-Queisser (SQ) limit. ${ }^{51} k$ is the Planck constant. $T$ is the temperature of the device and $E Q E_{\mathrm{EL}}$ (electroluminescence quantum efficiency) is the radiative quantum efficiency of the solar cell when it is measured as a light-emitting diode (LED). This equation 
quantifies the $V_{\text {oc }}$ by combining the optical gap and all the recombination loss pathways within a solar cell, and all the parameters are measurable or known, making it possible to compare the voltage losses in OSCs with other solar cells. In detail, $\Delta E_{1}$ is the energy loss due to the radiative recombination above the optical gap, which is unavoidable for any type of solar cells. $\Delta E_{2}$ is the energy loss caused by radiative recombination below the optical gap. This part is already below 50 $\mathrm{meV}$ in the latest OSCs with negligible energetic offsets, comparable to inorganic or perovskite solar cells. The last one $\Delta E_{3}$, the non-radiative recombination, is determined by the $E Q E_{E L} . \Delta E_{3}$ is typically 200-300 meV in state-of-the-art OSCs, significantly higher than highly efficient inorganic or perovskite solar cells. Hence, in order to reduce the voltage losses for next-generation OSCs, it is of critical importance to decrease $\Delta E_{3}$. To reduce the non-radiative loss of an OSC means to increase the $E Q E_{E L}$, which is determined by the following equation:

$$
\mathrm{EQE}_{\mathrm{EL}}=f_{\mathrm{e}-\mathrm{h}} * \beta * \eta_{\mathrm{PLQY}} * f_{\text {outcoupling }}
$$

where $f_{\mathrm{e}-\mathrm{h}}$ is the probability of balanced charge injection (when the numbers of electrons and holes injected are equal, this factor is equal to 1$), \beta$ is the probability of forming a correlated electron-hole pair or exciton from each pair of injected carriers, $\eta_{\mathrm{PLQY}}$ is the photoluminescence quantum yield (PLQY), and $f_{\text {outcoupling }}$ is the optical outcoupling coefficient. ${ }^{52}$

In order to demonstrate the importance of further increasing the PLQY, we here show the predicted relationship between PLQY and efficiency of non-fullerene OSCs for devices with different gaps (Figure 2). The EQE is assumed to be $85 \%$ above the bandgap; the $V_{O C}$ is determined by equation (1), where $\Delta E_{1}$ is calculated based on the bandgap, $\Delta \mathrm{E}_{2}$ is assumed to be $0.05 \mathrm{eV}$ due to non-ideal band edge, and $\Delta \mathrm{E}_{3}$ (nonradiative recombination losses) can be calculated from EQE outcoupling is assumed as $20 \%$ for a typical planar device. For organics, singlet and triplet excitons are theoretically generated in a 1:3 ratio by electronic excitation, while triplet excitons typically dissipate as heat rather than being converted into photons, limiting $\beta$ to $25 \% .^{53}$ The $\mathrm{FF}$ is based on the wellestablished empirical relationship $\mathrm{FF}=\gamma_{\mathrm{oc}}-\ln \left(\gamma_{\mathrm{oc}}+0.72\right) /\left(\gamma_{o c}+1\right)$, where $\gamma_{o c}=q V_{o c} / n k T, q$ is the elementary charge, $n$ is the diode ideality factor(here assumed as 1 ), $k$ is the Boltzmann constant and $T$ is the temperature. Assuming an absorption edge at $c a .900 \mathrm{~nm}$ and a high PLQY value of $2 \%$ for the blend, $20 \%$ PCE can be realized in an optimized device. Since the PLQY is a critical parameter, how to improve the PLQY of blends and ultimately to reduce the non-radiative loss of OSCs becomes the research hotspot.

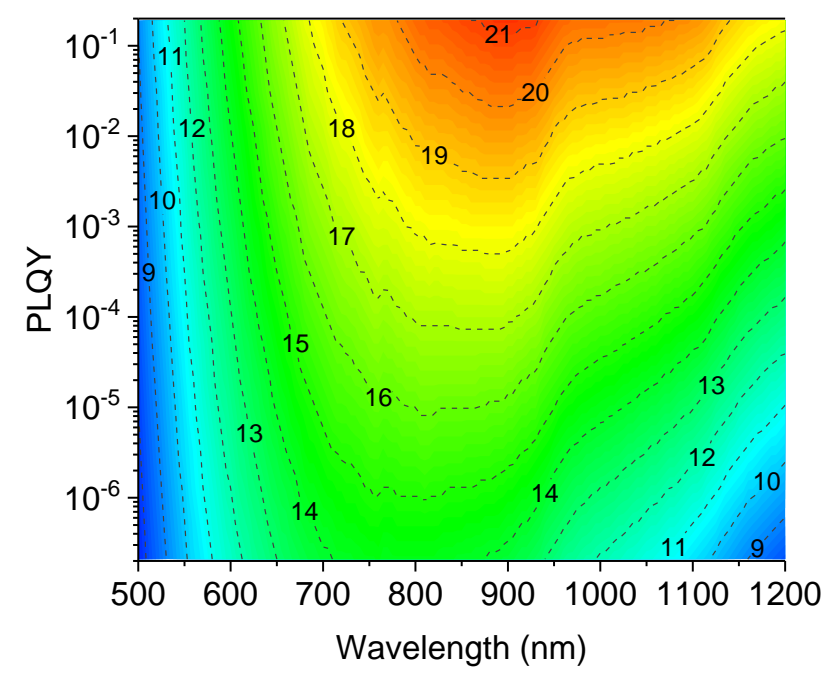

Figure 2. Efficiency prediction (plotted in color scale, with numbers on the contour lines representing PCE in \%) for NFAs-based OSCs with small energy offset. This figure highlights the importance of increasing PLQY to further enhance the PCEs to over $20 \%$. 
In fullerene-based blends, previous studies have demonstrated that the non-radiative voltage loss follows the energy-gap law, where the energy refers to the energy of CT states. ${ }^{54,55}$ The energy gap law presents intrinsic limitations to fullerene-based blends, as it indicates that there is a trade-off between high current densities and low voltage losses. However, in state-of-the-art non-fullerenebased systems, the Fourier-transform photocurrent spectroscopy EQE (FTPS-EQE) spectra and EL spectra of the blend devices quite often overlap with those of the devices based on the pristine lowgap components, indicating small energetic offset between the donor and acceptor materials. As such the non-radiative loss might be determined by the emission properties of the low-gap components due to hybridization between singlet excitons and CT states. ${ }^{56}$ In this case, highly luminescent $S_{1}$ states can help to increase the luminescence of the CT state through the intensity borrowing mechanism (hybridization) for low $\Delta \mathrm{G}_{S_{1}-C T_{1}}$ (defined as the energy difference between the $S_{1}$ and $\left.C T_{1}\right) .{ }^{56-58}$ This hybridization idea and "three-state model" explain how the negligible driving energy level in recent NFA-based results in a low non-radiative recombination (Figure 3). ${ }^{56,57}$ Thus, a large number of recent efforts have been focused on reducing the HOMO or LUMO offset between the donor and acceptor, and meanwhile increasing the PLQY of the lower-gap single component.

(a)

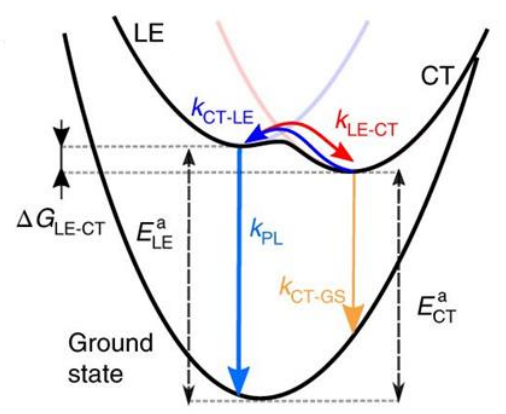

(b)

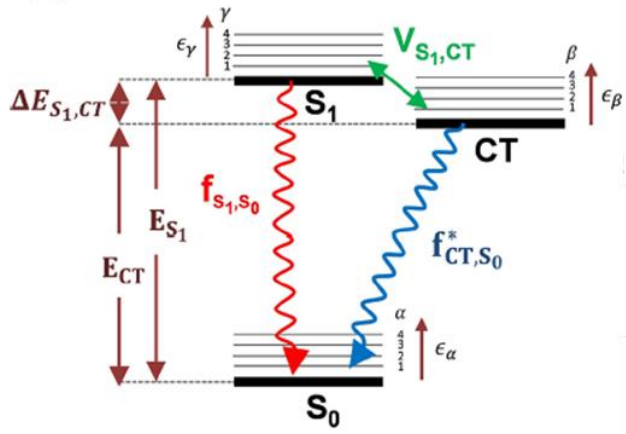

Figure 3. Electronic states and (non)radiative processes in OSCs.

(a) Schematic diagram of the potential energy surfaces for the ground (GS, also known as a $S_{0}$ ) state, local excited (LE, also known as a $\mathrm{S}_{1}$ ) state and charge-transfer $(\mathrm{CT})$ state. $E_{\mathrm{LE}}^{\mathrm{a}}$ and $E_{\mathrm{CT}}^{\mathrm{a}}$ denote the relaxed excitation energy from LE and $\mathrm{CT}$ to GS state, respectively. $k_{\mathrm{LE}-\mathrm{CT}}, k_{\mathrm{CT}-\mathrm{LE}}$ and $k_{\mathrm{CT}-\mathrm{GS}}$ denote the exciton dissociation, electron transfer from CT to LE state, and electron transfer from CT to GS state, respectively. The driving force for exciton dissociation is $\Delta \mathrm{G}_{\mathrm{LE}-\mathrm{CT}}=E_{\mathrm{LE}}^{\mathrm{a}}-E_{\mathrm{CT}}^{\mathrm{a}}$. Reprinted with permission from Qian et al. ${ }^{56}$ Copyright 2018 Springer Nature.

(b) Schematic of the three-state model, $V_{\mathrm{S} 1, \mathrm{CT}}$ is the coupling between $\mathrm{S}_{1}$ and $\mathrm{CT}$ state. Reprinted with permission from Eisner et al. ${ }^{57}$ Copyright 2019 American Chemical Society.

\section{DEVELOPMENT OF A-DA'D-A TYPE MOLECULES FOR ACHIEVING LOW VOLTAGE LOSSES}

Among the materials candidates for high efficiency devices, A-D-A-structured NFAs are extremely promising since they exhibit strong intramolecular charge-transfer (ICT) effect, superior energy level tunability, and good molecular crystallinity. Based on this successful design strategy, we introduced the electron-deficient $\left(A^{\prime}\right)$ unit in the middle of the central fused-ring of A-D-A molecule to form a ADA'D-A structure. Such schemes not only help to form multiple D-A interactions but also increase the backbone interaction between the adjacent acceptor molecules and/or the polymer donor in the blend film, facilitating the molecular aggregation and electron transport. These features allow the ADA'D-A NFAs to become potential candidates for achieving high external quantum efficiency and low voltage losses simultaneously. Although the unique A-DA'D-A molecules represent an exciting opportunity to improve the efficiency, what can we learn in terms of broader design strategies and 
insights from them? We summarize several important features from the chemical structure point of view:

(1) The A-DA'D-A NFAs configuration (such as Y6, Figure 4a) is an excellent combination of a ladder-type electron-deficient-core-based central fused ring (DA'D), electron-accepting end-group (A) and two $\mathrm{sp}^{2}$-hybridized nitrogen atoms in the pyrrole motif of the fused ring in a C2 symmetric manner;

(2) The electron-deficient-core has to be sterically hindered to prevent over aggregation, and the same time maintain an efficient intramolecular charge transport channel by the alkyl side chains onto the nitrogen $(N)$ atoms (the absorption of the A-DA'D-A molecule redshifts about $100 \mathrm{~nm}$ from the solution to solid film). Compared to previous designs, we now do not need to synthesize spiro-like structures; instead the sterically hindered side chains adopt an orthogonal conformation to the main plane (Figure $4 b$ ).

(3) With specific molecular geometry of the A-DA'D-A family (such as Y6), the dimerization could be formed in a unit cell (to counteract the molecular dipole moment) with a large quadrupole moment. The relatively narrow density of state (DOS) both in electron affinity and ionization energy could lead to a trap-free ambipolar transport (Figure $4 \mathrm{c}$ and d). The local excited state reorganization energy of $\mathrm{Y} 6$ is smaller than other NFAs, contributing to smaller voltage losses and making it less sensitive to the morphological variation in the blend films. ${ }^{59}$

The single crystal of the A-DA'D-A molecules confirms that the alkyl side chains onto the $\mathrm{N}$-atoms could greatly influence the stacking of adjacent molecules. ${ }^{60}$ The specific molecular geometry (curve shape) of them could form a twisted 1D transport channel and slipped packing motif, as seen from the main view and side view of Figure $4 \mathrm{e} .{ }^{61}$ Due to the dimerization in a crystal unit cell, the other set of Y6 molecules could form another 1D transport channel, which is quite different from the ITIC-like molecules, resulting in a multi-dimension interpenetrating network and transport channels. 
(a)

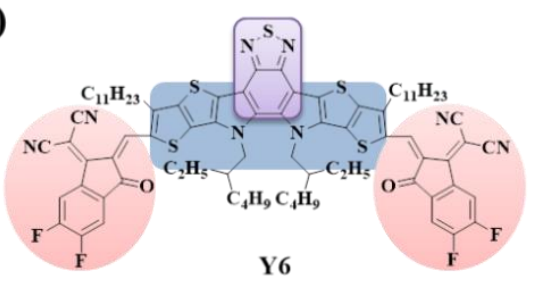

(c)

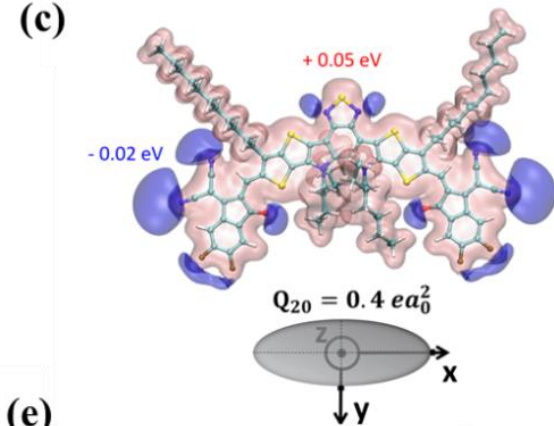

(e)

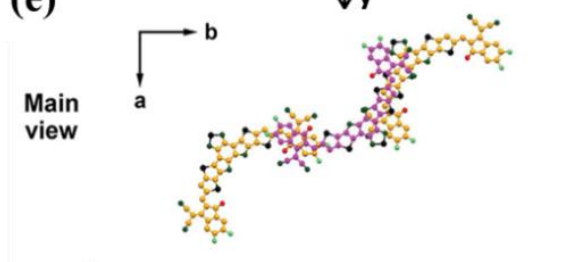

(b)

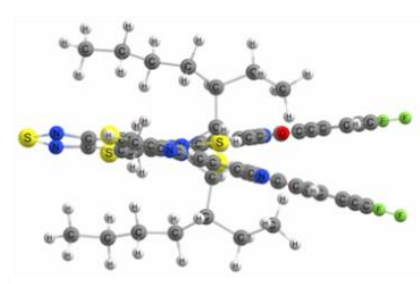

(d)
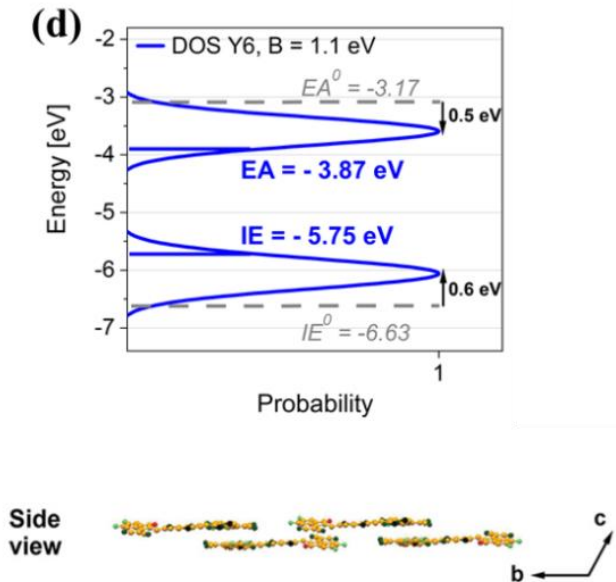
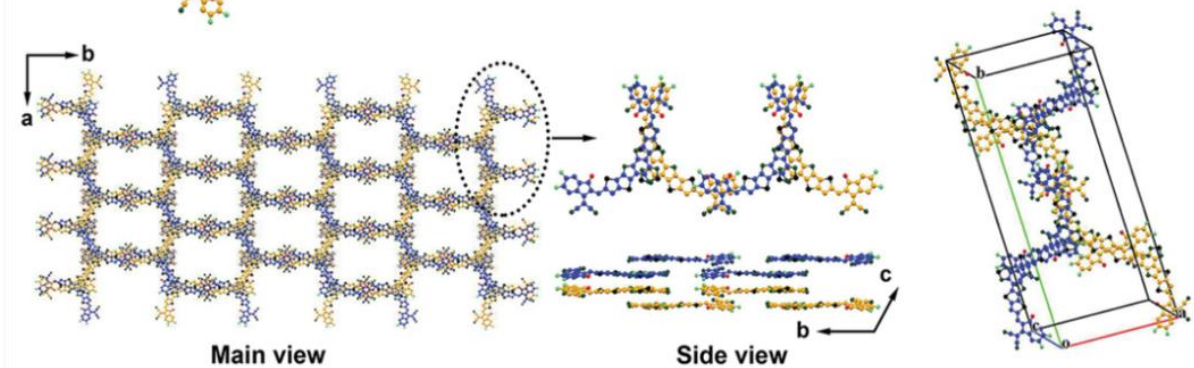

Figure 4. Unique features of the A-DA'D-A acceptor Y6.

(a) The Y6 molecules include a ladder-type electron-deficient-core-based central fused core (DA'D), electron-accepting end-group (A) and two $\mathrm{sp}^{2}$-hybridized nitrogen atoms in the pyrrole motif (ADA'D-A).

(b) Side view of the optimized geometry of $Y 6$ computed with $\omega-B 97 \times D / 6-31+G(d, p)$, indicating a clear twist in the backbone of a Y6 molecule. Reprinted with permission from Yuan et al. ${ }^{18}$ Copyright 2019 Elsevier.

(c) Isosurfaces of the electrostatic potential of Y6, together with the ellipsoid of the quadrupolar tensor. Reprinted with permission from Perdigon-Toro et al. ${ }^{59}$

(d) Calculated DOS for electrons (EA) and holes (IE) in a model crystal of Y6. Reprinted with permission from Perdigon-Toro et al. ${ }^{59}$

(e) The single crystal structure of Y6. Reprinted with permission from Zhu et al. ${ }^{61}$ Copyright 2020 Wiley.

\section{PERSPECTIVES AND CHALLENGES FOR BOTH MATERIAL AND DEVICE DEVELOPMENT}

Despite these significant breakthroughs, the success of A-DA'D-A type NFAs results from around three years' development, from BZIC, the first-generation product of A-DA'D-A type NFAs in Zou's group in 2017 with a PCE of $6 \%$, to Y18 with a high PCE of $17 \% .62-64$ These progresses originate from 
continuing exploration of the underlying relationship and mechanism between the molecular structures, packing and high PLQY as well as the effective charge generation.

\section{Perspectives and Challenges on the Molecular Design}

Choosing the central A' unit in A-DA'D-A molecules. The strategy of using a conjugated "push-pull" structure in designing high-performance polymers has been applied to construct NFAs. As mentioned before, one of the most important features in our molecular design strategy is to introduce an electron-deficient $\left(A^{\prime}\right)$ segment in the middle of the central core to form a fused $D A^{\prime} D$ structure. This unusual core can tune the energy level to match a small energy offset with high-performance donor materials and form the $\mathrm{Y}$-shape molecular geometry simultaneously, resulting in a multi-dimension interpenetrating network and molecular interaction. Although benzothiadiazole (BT) unit based molecule $Y 6$ has made great success, the performance of the A-DA'D-A molecules still has much room for improvement. The HOMO offset ( $\triangle E_{\text {номо }}$ ) between the control material system PM6 and Y6 ( $\sim .1 \mathrm{eV}$ ) can be further decreased. In addition, the PLQY of PM6:Y6 blend film is only $2.8^{*} 10^{-4}$, which is about 70 times smaller than the target PLQY value for a PCE of $20 \%$.

Accordingly, we proposed a simple design strategy that by carefully optimizing the $A^{\prime}$ unit in the ADA'D-A molecules, new A-DA'D-A molecules with higher PLQY value could be achieved. For example, we replaced the BT unit of $Y 6$ with benzotriazole (BTA) unit, forming a new DA'D fused core. Based on this BTA-based NFA (Y11), the optical gap as well as the non-radiative loss were reduced significantly. ${ }^{63}$ This is explained by the fact that the BTA unit has a weaker electron-withdrawing

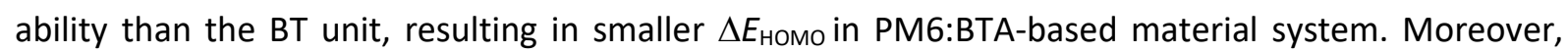
the PLQY of PM6:Y11 shows a higher value $1.3^{*} 10^{-3}$ (near five times higher than the BT unit-based blend film). As a result, the $\Delta E_{3}$ of PM6:Y11-based device is as low as $0.20 \mathrm{eV}$.

Encouraged by the success of the BTA unit, we can further tune the $A^{\prime}$ unit. Figure $5 a$ shows an empirical electron-withdrawing ability trend of representative acceptor units, providing different options for the $A^{\prime}$ unit in the A-DA'D-A molecules. This acceptor unit trend is based on the comparison of reduction potentials and optical gaps of reported polymers. ${ }^{65}$ We note that this trend may vary due to the influences of other factors, such as steric hindrance and significant differences in $\pi$-stacking. ${ }^{66}$

In addition, In the field of LEDs, it is well known that there is a trade-off between the charge transport and light emission in a light-emitting layer. For good charge transport, the close interactions (van der Waals forces) of the chromophores are beneficial for charge transport. However, for efficient light emission, a close interaction is deemed unfavorable to fluorescence because of the formation of excimers from the aggregation. Excimers formation may lead to a change of emission spectrum and a reduction in the PLQY (unless the molecules exhibit a special "magic-angel" type stacking (M-aggregate)). ${ }^{67}$ By combining the concept of M-aggregate and the recently reported crystal structure of NFAs, we propose to design the isomeric NFAs (differ only by the molecular geometry) to find the suitable packing to balance the charge transport and light emission (Figure $5 b$ ), and to study the relationship between chemical structure conformation and non-radiative recombination losses.

Development of "quasi-polymer" molecules. All-polymer solar cells (all-PSCs) have attracted considerable attention recently due to the unique advantage of morphological stability and mechanical robustness. From the materials point of view, the development of polymer materials could overcome the disadvantages of small molecular materials such as a strong tendency to crystallize at elevated temperatures (resulting in overlarge domain size and unfavorable geminate and non-geminate recombination) and relatively poor mechanical properties. However, the molecular weight polydispersity, poor batch-to-batch reproducibility and end-group variation are the 
shortcomings for the polymer material applications. When translating OSC technology from laboratory prototypes to commercial products, the easy processes with roll-coated large-area modules should also be considered. Here, we highlight the fused electron-deficient segment based "quasi-polymer" molecules (Figure 5c). The "quasi-polymer" molecules, such as oligomer molecule and branched macromolecules, exhibit well-defined chemical structures and excellent film forming properties. By modifying the structure of fused electron-deficient segment, the roll-coated large-area OSCs with low voltage loss and high morphology stability can be expected.

(a)

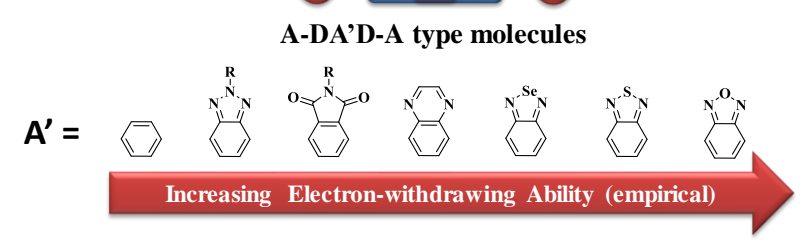

(b)

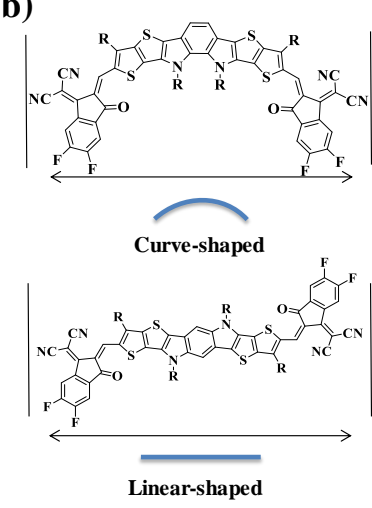

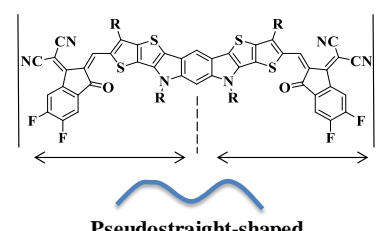

Pseudostraight-shaped

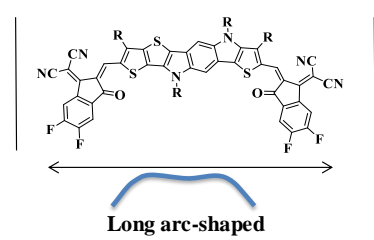

(c)
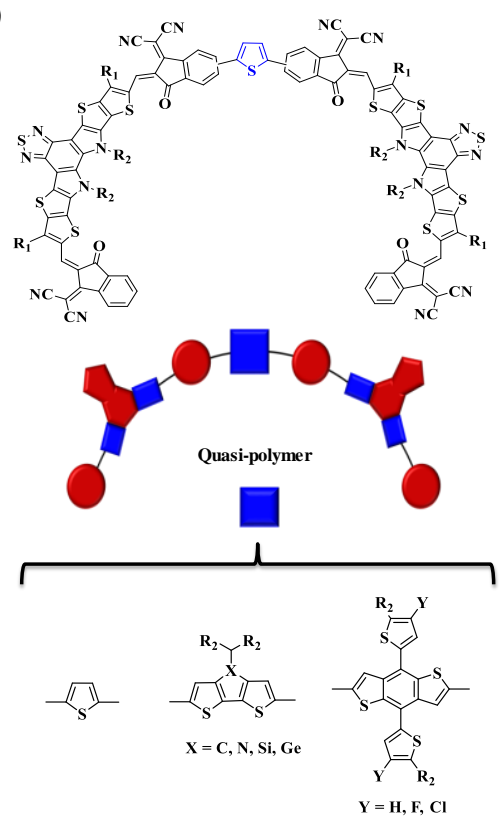

Figure 5. Strategies and typical molecular structures of newly designed NFAs for OSCs

(a) Employing $A^{\prime}$ acceptor units with different electron-withdrawing ability in A-DA'D-A type molecules.

(b) The molecular structures of NFAs and simulated diagram of the geometry of the isomeric NFAs.

(c) The molecular structure of "quasi-polymer" NFA.

Decreasing the energetic disorder of organic materials. It is well acknowledged that tail states in amorphous silicon cause a reduction in $V_{\text {oc }}$ by trapping carriers, leading to unfavorable non-radiative recombination. ${ }^{68}$ Similarly, a broad distribution of electronic DOS in organic materials can lead to tail states, providing channels for non-radiative recombination. ${ }^{69,70}$ Bisquert and coworkers showed that the energetic disorder plays an important role in energy losses. This is related to the carrier thermalization in the tail of DOS and the consequent entropic limitation to the free energy rise. ${ }^{71}$

In order to understand how the energetic disorder can be influenced by structural features of organic molecules, we measured the sub-gap absorptions in the corresponding films to evaluate their static disorder (Figure 6a). As a result of localized electronic states at the band edges, the optical absorption coefficient $\alpha$ in the low photon energy range follows the Urbach rule $\alpha=\alpha_{o} \exp \left(\frac{E-E_{g}}{E_{U}}\right){ }^{72}$ where $\alpha_{0}$ is the absorption coefficient at $E_{\mathrm{g}}, E$ is the incident photon energy and $E_{\mathrm{U}}$ is the Urbach energy. Zou et al. recently presented an efficient strategy to decrease the $E_{u}$ and DOS widths by introducing the alkyl chain on the periphery of the fused central core of the A-DA'D-A acceptor to achieve an ordered molecular orientation (Figure $6 \mathrm{~b}$ and c). ${ }^{73}$ Moreover, it is widely accepted that the charge transport in organic semiconductors is affected by a degree of structural disorder in both the manifold of localized hopping sites and the local variations of molecular packing. By introducing the alkyl chain on the $\beta$ position of DA'D central core, a high degree unified molecular conformation 
as well as the crystallinity of the molecules can be significantly improved. As a result, the electron mobility of terminal alkylated A-DA'D-A molecule Y18 is five times higher than non-alkylated Y 3 in the BHJ films. ${ }^{73,74}$
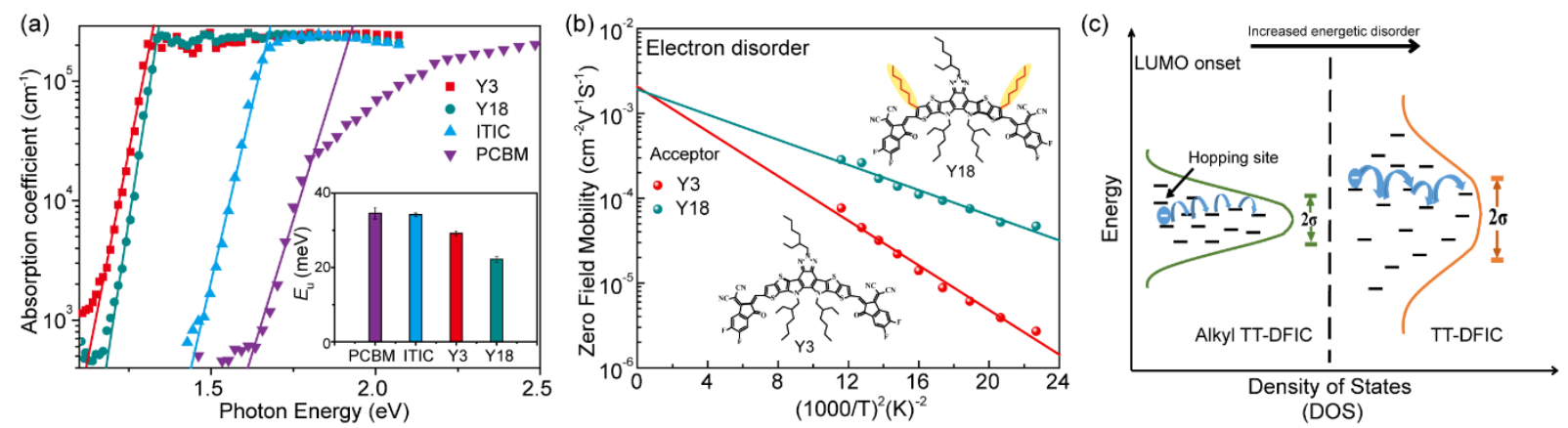

Figure 6. Urbach energy and energetic disorder of the typically acceptor molecules for OSCs.

(a) Highly sensitive photothermal deflection spectroscopy (PDS) derived absorption spectra of PCBM, ITIC, Y3 and Y18 neat films;

(b) Gaussian Disorder Model (GDM) analysis for Y3 and Y18 based blend films: electron zero-field mobilities versus the square of reciprocal temperature. Solid lines are the best linear fittings to the experimental data. Energetic disorder $\sigma$ and high-temperature-limited mobility $\mu_{\infty}$ can be extracted from the slopes and $y$-intercept of the data plots. Reprinted with permission from Yuan et al. ${ }^{73}$ Copyright 2020 Springer Nature.

(c) Schematic illustration of the impact of with or without alkyl side chains on electron transport and energetic disorder. Reprinted with permission from Yuan et al. ${ }^{73}$ Copyright 2020 Springer Nature.

\section{Perspectives and Challenges on Device Engineering for Low Voltage Losses}

Morphology optimization. In addition to materials themselves, the morphology can also affect the non-radiative recombination and hence the voltage losses. The hierarchical phase separation of solution-processed OSCS plays an important role in reducing the non-radiative loss. An ideal hierarchical morphology includes optimized domain size, domain purity and D/A interface, which also significantly affect the charge separation and charge extraction processes. Fortunately, it is possible to achieve various hierarchical morphology by controlling the kinetics and thermodynamics of film formation, for example, by choosing different solvents (Figure 7), additives, annealing temperature and blend ratios, etc. ${ }^{61}$ Many efforts have been devoted to improving the emissive efficiency of the blend system from the perspective of molecular conformation and phase structure for active layers. ${ }^{75}$
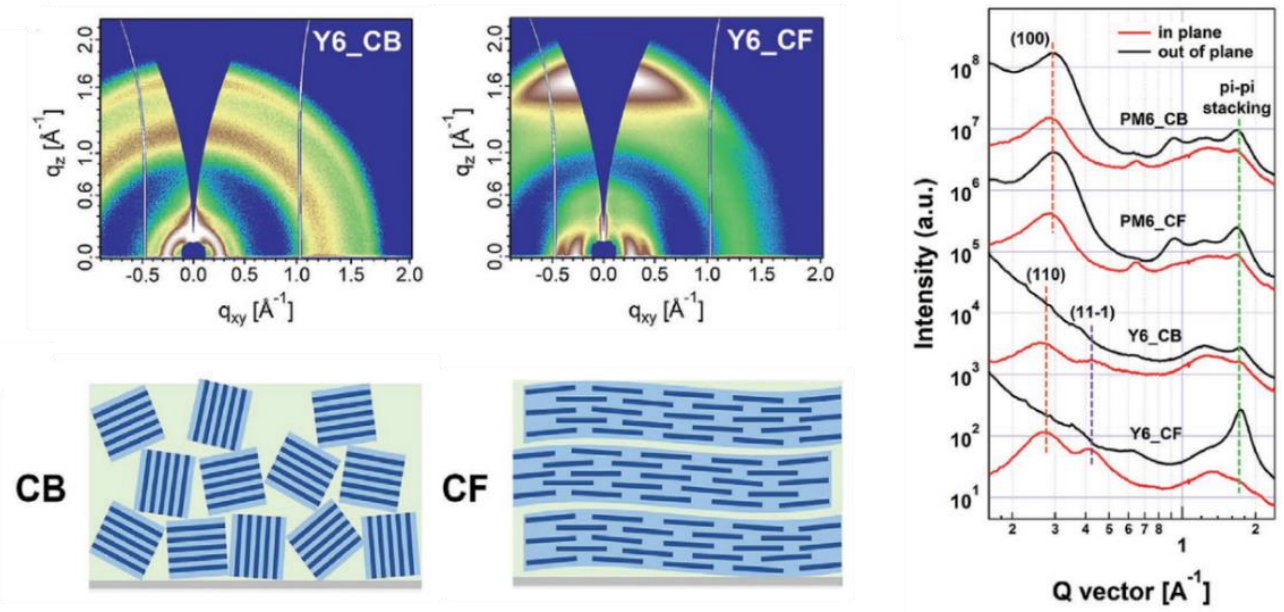

Figure 7. GIWAXS images, scattering profiles and sketch maps for neat and blend films of Y6 processed with different solvents. Reprinted with permission from Zhu et al. ${ }^{59}$ Copyright 2020 Wiley. 
As mentioned before, increasing the PLQY of narrow gap materials could decrease the nonradiative energy loss. In addition to improving the PLQY of pure acceptor materials, how to ensure the overall high PLQY of a blended film is also important. For solution-processed OSCs, quantitative control of the conformation and aggregation effect of components is the key to enable effective phase separation. Although some previous results showed that the pre-aggregation behavior of donor polymer plays an important role when mixed with acceptor materials, ${ }^{76}$ the film-forming process of NFAs seems to have been ignored. An interesting phenomenon has been observed by the A-DA'D-A NFA-based blend films. As shown in Figure 8, the pristine films of PM6, Y11 and their blend films exhibit preferred face-on molecular packing. However, it can be seen that the (100) diffraction peak in the blend film showed a new diffraction at the out-of-plane (OOP) direction (from $0.54-0.59$ $\left.\AA^{-1}\right)$. It might be enhanced by molecular packing originated from acceptors, according to the peak position of pure films. This result showed that the A-DA'D-A NFA blend films have more molecules stacking regularly in the OOP direction, which is different from the A-D-A NFA ITIC-series film's packing.

This phenomenon might imply strong relationship between the "reconstructed" morphology and the charge generation as well as the luminescence yield of the blend film. As we know, the more ordered molecular packing in multi-dimensional direction is beneficial for achieving effective charge transport. How to reduce energy losses while ensuring optimized transport by tuning the balance between solvent-molecule interaction and solubility etc. in solution might be critical to obtain high efficiency devices. In addition, in high-efficiency NFA blend systems, effective strategies (such as adjusting the relative solubility for donor and acceptor, increasing the self-assembly/pre-aggregation behavior of acceptors etc.) need to be considered to minimize the aspects from the donor components to maximum increase the PLQY of blend active layer. We believe that a more detailed study of morphological evolution process can lead to a deep understanding of the non-radiative recombination in the NFAs-based OSCs.
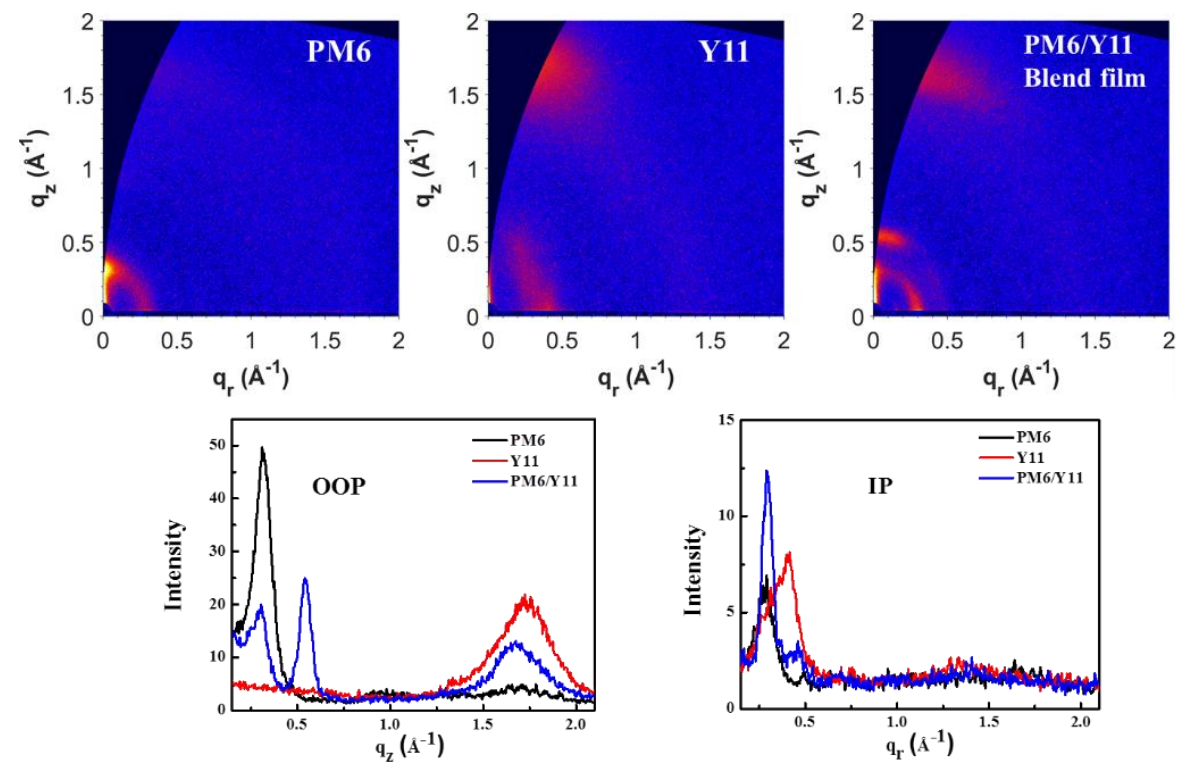

Figure 8. GIWAXS images and scattering profiles of PM6, Y11 and PM6/Y11 blend films. Reprinted with permission from Yuan et al. ${ }^{73}$ Copyright 2020 Springer Nature.

Ternary blend strategy. Typically, the third component of the ternary organic solar cells (TOSCs) can improve the $V_{o c}$ via tuning the energy levels of the charge transfer states. Interestingly, Hou and 
colleagues recently reported that the third component can also suppress the non-radiative recombination energy loss in the ternary organic solar cells, contributing to the improvement of the $V_{\text {oc. }}$ In their study, it was proposed that the third component can reduce the aggregation of the original component and thus suppress the aggregation caused exciton quenching, leading to the enhanced PLQY of the pristine materials as well as the EQE $\mathrm{EL}_{\mathrm{EL}}$ of the devices. ${ }^{77,78}$

In addition, Blom and coworkers showed that the fullerene as the third component in the ternary solar cells can suppress the trap states and promote electron mobility, leading to a more balanced charge transport. ${ }^{79}$ It was also reported that the EQE $E_{\mathrm{EL}}$ of the devices can be enhanced by suppressing the trap effects, in which the emission components are diluted in the insulator matrix. The suppressed trap states and more balanced charge transport might be also the reasons for the improved EQEEL in TOSCS. Although the third component helping to improve the EQE $\mathrm{ELL}_{\mathrm{EL}}$ inspires a potential method of reducing the non-radiative energy loss in the OSCs, several important issues need to be further investigated. Firstly, the reduced aggregation of the pristine material may be detrimental for the already optimized morphology of the binary devices, possibly resulting in reduced PCE. Secondly, the trap dilution by adding the insulators will decrease the absorption of the active layer and thus the photocurrent, if the thickness of the active layer is kept the same. Finally, ensuring charge injection balance by designing the particular third components, which help to increase the $\mathrm{EQE}_{\mathrm{EL}}$ of OSC devices, requires more efforts.

\section{SUMMARY AND OUTLOOKS}

Historically, it was believed that significant energetic offset between the donor and acceptor materials (usually " $0.3 \mathrm{eV}$ ") was needed to split the strongly bound excitons at the BHJ OSCs, resulting in large voltage losses. However, new NFAs have now demonstrated that the IQE can reach $90 \%$ even when the energetic offset approaches zero. This suggests that there is no intrinsic compromise between photocurrent generation and $V_{\text {oc }}$ for low offset systems and that the development of new materials are really encouraging for the OSCS community. In this perspective, we have discussed the relationships between open-circuit voltage, CT state properties and molecule characteristics. We have provided our understanding of design strategies for decreasing the voltage losses in high-performance NFA OSCs, from both materials and devices perspectives. Although some effects have been touched during the past few years, including PLQY of the pristine materials, tail states, morphology, ternary strategies, more efforts are required to further decrease the nonradiative recombination.

In addition, some open questions require further investigations. For example, do the thermal motions, the triplet states, and the domain purity of the individual phase and intermixed regions etc. also affect the voltage losses? Friend and colleagues examined the spin statistics in the CT states via bimolecular encounters of free charges for understanding the nature of the non-radiative recombination mechanisms in fullerene-based OSCs. ${ }^{80,81}$ Decay from the spin-triplet $\left({ }^{3} \mathrm{CT}\right)$ state to the GS state is spin-forbidden, thus a favorable non-radiative recombination can occur when ${ }^{3} \mathrm{CT}$ relaxes to the $T_{1}$ state and then decays to $S_{0 .}{ }^{82}$ Although this has been seen for the fullerene-based material systems, little is known about the triplets in the NFA OSCs at this moment.

In some applications, due to the advantage of high tunable NFA structures, single or multijunction OSC devices (with large voltages) also can be expected to harvest inhomogeneous and weak light, producing sufficient power to drive charge into the low-power electronics applications such as remote sensors, portable e-paper displays, powered RFID systems. ${ }^{83,}{ }^{84}$ Once translating OSC technology from laboratory to commercial products, we have to pay careful attention to industrial requirements, for example the cost and stability of photovoltaic materials and devices, the largescale module and possibilities to process in a green solvent. 


\section{ACKNOWLEDGEMENTS}

Y. Zou acknowledges National Natural Science Foundation of China (NSFC) (21875286), the National Key Research \& Development Projects of China (2017YFA0206600), Science Fund for Distinguished Young Scholars of Hunan Province (2017JJ1029). F. G. acknowledges the financial support the Swedish Research Council VR (2018-06048), the Swedish Energy Agency Energimyndigheten (2016010174), and the Stiftelsen för Strategisk Forskning through a Future Research Leader program (FFL18-0322). M.L. thanks NSERC for its support. The authors also thank Dr. Deping Qian, Mr. Ye Liu, Mr. Chujun Zhang and Mrs. Wei Liu for providing important insights on the manuscript.

\section{AUTHOR CONTRIBUTIONS}

J. Y., F. G. and Y. Z. proposed the topic of the manuscript. J. Y. investigated the literature and wrote the manuscript. J. Y., H. Z., R. Z, Y. W., F. G., and Y. Z. discussed the manuscript and commented on it. J. H., M. L., X. Z., F. H. and Y. L. revised the review critically for important intellectual content. All authors read and approved the final version of the manuscript.

\section{REFERENCES AND NOTES}

1. Matiko, J.W., Grabham, N.J., Beeby, S.P. and Tudor, M.J. (2014). Review of the application of energy harvesting in buildings. Meas. Sci. Technol. 25, 012002.

2. Allouhi, A., El Fouih, Y., Kousksou, T., Jamil, A., Zeraouli, Y., \& Mourad, Y. (2015). Energy consumption and efficiency in buildings: current status and future trends. J. Clean. Prod.. 109, 118-130.

3. Li, G., Shrotriya, V., Huang, J., Yao, Y., Moriarty, T., Emery, K. and Yang, Y. (2005).Highefficiency solution processable polymer photovoltaic cells by self-organization of polymer blends. Nat. Mater. 4, 864-868.

4. Heeger, A.J. (2014). 25th anniversary article: Bulk heterojunction solar cells: understanding the mechanism of operation. Adv. Mater. 26, 10-27.

5. Yu, G., Gao, J., Hummelen, J.C., Wudl, F. and Heeger, A.J. (1995). Polymer Photovoltaic Cells: Enhanced Efficiencies via a Network of Internal Donor-Acceptor Heterojunctions. Science. 270, 1789-1791.

6. Mehrotra, S., Rawat, P., Debbarma, M. and Sudhakar, K. (2014). Performance of a solar panel with water immersion cooling technique. International Journal of Science, Environment and Technology. 3, 1161-1172.

7. Best Research-Cell Efficiency Chart, NREL. http://www.nrel.gov/pv/cell-efficiency.html

8. Misra, V., Bozkurt, A., Calhoun, B., Jackson, T., Jur, J., Lach, J., Lee, B., Muth, J., Oralkan, Ö., Özturk, SM., Trolier-McKinstry, S., Vashaee, D., Wentzloff, D. and Zhu, Y. (2015) Flexible technologies for self-powered wearable health and environmental sensing. Proc. leee. 103, 665-681.

9. Park, S., Heo, S. W., Lee, W., Inoue, D., Jiang, Z., Yu, K., Jinno H., Hashizume D., Sekino M., Yokota T., Fukuda K., Tajima K., and Someya T. (2018). Self-powered ultra-flexible electronics via nano-grating-patterned organic photovoltaics. Nature. 561, 516-521.

10. Sartori, I., Napolitano, A. and Voss, K. (2012). Net zero energy buildings: A consistent definition framework. Energy Build. 48, 220-232. 
11. Peng, C., Huang, Y. and $\mathrm{Wu}$, Z. (2011). Building-integrated photovoltaics (BIPV) in architectural design in China. Energy Build. 43, 3592-3598.

12. Brus, V. V., Lee, J., Luginbuhl, B. R., Ko, S. J., Bazan, G. C. and Nguyen, T. Q (2019). SolutionProcessed Semitransparent Organic Photovoltaics: From Molecular Design to Device Performance. Adv Mater. 31, e1900904.

13. Forberich, K., Guo, F., Bronnbauer, C. and Brabec, C.J. (2015). Efficiency Limits and Color of Semitransparent Organic Solar Cells for Application in Building-Integrated Photovoltaics. Energy Technol. 3, 1051-1058.

14. Chamberlain, G. (1983). Organic solar cells: A review. Solar cells. 8, 47-83.

15. Lu, L., Zheng, T., Wu, Q., Schneider, A. M., Zhao, D. and Yu, L. (2015). Recent Advances in Bulk Heterojunction Polymer Solar Cells. Chem Rev. 115, 12666-12731.

16. Dennler, G., Scharber, M.C. and Brabec, C.J. (2009). Polymer-Fullerene Bulk-Heterojunction Solar Cells. Adv Mater. 21, 1323-1338.

17. Su, Y.-W., Lan, S.-C. and Wei, K.-H. (2012). Organic photovoltaics. Mater. Today. 15, 554-562.

18. Yuan, J., Zhang, Y., Zhou, L., Zhang, G., Yip, H. L., Lau, T. K., Lu, X., Zhu, C., Peng H., Johnson P., Leclerc, M., Cao, Y., Ulanski, J., Li, Y. and Zou Y. (2019). Single-junction organic solar cell with over $15 \%$ efficiency using fused-ring acceptor with electron-deficient core. Joule. 3, 11401151.

19. Cui, Y., Yao, H., Zhang, J., Zhang, T., Wang, Y., Hong, L., Xian, K., Xu, B., Zhang, S., Peng, J., Wei, Z., Gao, F., and Hou, J. (2019). Over $16 \%$ efficiency organic photovoltaic cells enabled by a chlorinated acceptor with increased open-circuit voltages. Nat. Commun. 10, 2515.

20. Liu, Q., Jiang, Y., Jin, K., Qin, J., Xu, J., Li, W., Xiong, J., Liu, J., Xiao, Z., Sun, K., Yang, S., Zhang, X., and Ding, L. (2020). 18\% efficiency organic solar cells. Sci. Bull. 65, 272-275.

21. Fan, B., Zhang, D., Li, M., Zhong, W., Zeng, Z., Ying, L., Huang, F., and Cao, Y. (2019). Achieving over $16 \%$ efficiency for single-junction organic solar cells. Sci China Chem. 62, 746752.

22. Jiang, K., Wei, Q., Lai, J. Y. L., Peng, Z., Kim, H. K., Yuan, J., Ye, L., Ade, H., Zou, Y., and Yan, H. (2019). Alkyl Chain Tuning of Small Molecule Acceptors for Efficient Organic Solar Cells. Joule. 3, 3020-3033.

23. Sun, H., Liu, T., Yu, J., Lau, T. K., Zhang, G., Zhang, Y., Su, M., Tang, Y., Ma, R., Liu, B., Liang, J., Feng, K., Lu, X., Guo, X., Gao, F. and Yan, H. (2019). A monothiophene unit incorporating both fluoro and ester substitution enabling high-performance donor polymers for non-fullerene solar cells with $16.4 \%$ efficiency. Energ Environ Sci. 12, 3328-3337.

24. Chen, J. D., Li, Y. Q., Zhu, J., Zhang, Q., Xu, R. P., Li, C., Zhang, Y. X., Huang, S., Zhan, X., You, W., and Tang, J. X. (2018). Polymer Solar Cells with 90\% External Quantum Efficiency Featuring an Ideal Light- and Charge-Manipulation Layer. Adv Mater. 30, e1706083.

25. Huang, F., Bo, Z. S., Geng, Y. H., Wang, X. H., Wang, L. X., Ma, Y. G., Hou, J. H., Hu, W. P., Pei, J., Dong, H. L., Wang, S., Shuai, Z. G., Li, Y. F. and Cao, Y. (2019). Study on optoelectronic polymers: an overview and outlook. Acta Polym Sin. 50, 988-1046.

26. Lin, Y., Wang, J., Zhang, Z. G., Bai, H., Li, Y., Zhu, D., and Zhan, X. (2015). An electron acceptor challenging fullerenes for efficient polymer solar cells. Adv Mater. 27, 1170-1174.

27. Li, S., Li, C. Z., Shi, M., \& Chen, H. (2020). New Phase for Organic Solar Cell Research: Emergence of Y-Series Electron Acceptors and Their Perspectives. ACS Energy Lett. 5, 15541567.

28. Yan, C. , Barlow, S., Wang, Z., Yan, H., Jen, A. K-Y, Marder, S., and Zhan, X. (2018). Nonfullerene acceptors for organic solar cells. Nat. Rev. Mater. 3, 18003.

29. Kan, B., Zhang, J., Liu, F., Wan, X., Li, C., Ke, X., Wang, Y., Feng, H., Zhang, Y., Long, G., Friend, R. H., Bakulin, A. A., and Chen, Y. (2018). Fine-Tuning the Energy Levels of a Nonfullerene Small-Molecule Acceptor to Achieve a High Short-Circuit Current and a Power Conversion Efficiency over 12\% in Organic Solar Cells. Adv Mater. 30, 1704904. 
30. Baran, D. Ashraf, R. S., Hanifi, D. A., Abdelsamie, M., Gasparini, N., Röhr, j. a., Holliday, S., Wadsworth, A., Lockett, S., Neophytou, M., Emmott, C. J.M., Nelson, J., Brabec, C. J., Amassian, A., Salleo, A., Kirchartz, T., Durrant J. R. andlain Culloch, M. (2017). Reducing the efficiency-stability-cost gap of organic photovoltaics with highly efficient and stable small molecule acceptor ternary solar cells. Nat Mater. 16, 363-369.

31. Li, X.J., Pan, F., Sun C.K., Zhang, M., Wang, Z. W., Du J.Q., Wang J., Xiao, M., Xue, L.W., Zhang, Z.G., Zhang, C. F., Liu, F. and Li, Y. F. (2019). Simplified synthetic routes for low cost and high photovoltaic performance n-type organic semiconductor acceptors. Nat. Commun. 10, 519.

32. Liu, D. Y., Wang, J.Y., Gu, C.Y., Li, Y.H., Bao, X.C., and Yang, R.Q. (2018). Stirring Up Acceptor Phase and Controlling Morphology via Choosing Appropriate Rigid Aryl Rings as Lever Arms in Symmetry-Breaking Benzodithiophene for High-Performance Fullerene and Fullerene-Free Polymer Solar Cells. Adv Mater. 30, 1705870.

33. Xu, X. P., Feng, K., Bi, Z.Z., Ma, W., Zhang, G.J. and Peng, Q. (2019). Single-Junction Polymer Solar Cells with $16.35 \%$ Efficiency Enabled by a Platinum(II) Complexation Strategy. Adv Mater. 31, e1901872.

34. Zhang, T., Zeng, G., Ye, F., Zhao, X. and Yang, X. (2018). Efficient Non-Fullerene Organic Photovoltaic Modules Incorporating As-Cast and Thickness-Insensitive Photoactive Layers. Adv Energy Mater. 8, 1801387.

35. Huang, H., Guo, Q.X., Feng, S.Y., Zhang, C.E., Bi, Z.Z., Xue, W.Y., Yang, J.J., Song, J.S., Li, C.H., Xu, X.J., Tang, Z., Ma, W. and Bo, Z.S. (2019). Noncovalently fused-ring electron acceptors with near-infrared absorption for high-performance organic solar cells. Nat. Commun. 10, 3038.

36. Wu, Q., Guo, J., Sun, R., Guo, J., Jia, S.F., Li, Y.W., Wang, J.B. and Min, J. (2019). Slot-die printed non-fullerene organic solar cells with the highest efficiency of $12.9 \%$ for low-cost PVdriven water splitting. Nano Energy. 61, 559-566.

37. Ni, Z.J., Wang, H.L., Zhao, Q., Zhang, J.Q., Wei, Z.X., Dong, H.L. and Hu, W.P. (2019). Ambipolar Conjugated Polymers with Ultrahigh Balanced Hole and Electron Mobility for Printed Organic Complementary Logic via a Two-Step C-H Activation Strategy. Adv Mater. 31, 1806010.

38. Zhou, R.M., Jiang, Z.Y., Yang, C., Yu, J.W., Feng, J.R., Adil, M.A., Deng, D., Zou, W.J., Zhang, J.Q., Lu, K., Ma, W., Gao, F. and Wei, Z.X. (2019). All-small-molecule organic solar cells with over 14\% efficiency by optimizing hierarchical morphologies. Nat. Commun. 10, 5393.

39. Feng, G.T., Li, J.Y., Colberts, F.J.M., Li, M.M., Zhang, J.Q., Yang, F., Jin, Y.Z., Zhang, F.L., Janssen, R.A.J, Li, C. and Li , W.W.(2017). "Double-Cable" Conjugated Polymers with Linear Backbone toward High Quantum Efficiencies in Single-Component Polymer Solar Cells. J Am Chem Soc. $139,18647-18656$.

40. Sun, H., Guo, X., and Facchetti, A. (2020). High-Performance n-Type Polymer Semiconductors: Applications, Recent Development, and Challenges. Chem. 6, 1310-1326.

41. Yan, T., Song, W., Huang, J., Peng, R., Huang, L. and Ge, Z. (2019). 16.67\% Rigid and $14.06 \%$ Flexible Organic Solar Cells Enabled by Ternary Heterojunction Strategy. Adv Mater. 31, e1902210.

42. Fu, Y., Wang, B., Qu, J., Wu, Y., Ma, W., Geng, Y., Han, Y.C. and Xie, Z. (2016). Fullerene-Free Polymer Solar Cells with Open-Circuit Voltage above 1.2 V: Tuning Phase Separation Behavior with Oligomer to Replace Polymer Acceptor. Adv Funct Mater. 26, 5922-5929.

43. Wang, J., Zheng, Z., Zhang, D., Zhang, J., Zhou, J., Liu, J., Xie, S.K., Zhao, Y., Zhang, Y., Wei, Z.X., Hou, J.H, Tang Z.Y. and Zhou, H. (2019). Regulating Bulk-Heterojunction Molecular Orientations through Surface Free Energy Control of Hole-Transporting Layers for HighPerformance Organic Solar Cells. Adv Mater. 31, e1806921.

44. Liang, Q., Jiao, X., Yan, Y., Xie, Z., Lu, G., Liu, J., and Han, Y. (2019). Separating Crystallization Process of P3HT and O-IDTBR to Construct Highly Crystalline Interpenetrating Network with Optimized Vertical Phase Separation. Adv Funct Mater. 29, 1807591. 
45. Zhou, Z., Xu, S., Song, J., Jin, Y., Yue, Q., Qian, Y., Liu, F., Zhang, F.L. and Zhu, X. (2018). Highefficiency small-molecule ternary solar cells with a hierarchical morphology enabled by synergizing fullerene and non-fullerene acceptors. Nat Energy. 3, 952-959.

46. Hou, J., Inganas, O., Friend, R.H. and Gao, F. (2018). Organic solar cells based on nonfullerene acceptors. Nat Mater. 17, 119-128.

47. Liu, X., Li, Y., Ding, K. and Forrest, S. (2019). Energy Loss in Organic Photovoltaics: Nonfullerene Versus Fullerene Acceptors. Phys. Rev. Appl. 11, 024060.

48. Vandewal, K., Mertens, S., Benduhn, J. and Liu, Q. (2020). The Cost of Converting Excitons into Free Charge Carriers in Organic Solar Cells. J. Phys. Chem. Lett. 11, 129-135.

49. Yao, J. et al. (2015). Quantifying Losses in Open-Circuit Voltage in Solution-Processable Solar Cells. Phys. Rev. Appl. 4, 014020.

50. Linderl, T. , Zechel, T., Brendel, M., González, D.M., Müller-Buschbaum, P., Pflaum, J. and Brütting, W. (2017). Energy Losses in Small-Molecule Organic Photovoltaics. Adv Energy Mater. 7, 1700237.

51. Shockley, W. and Queisser, H.J. (1961). Detailed balance limit of efficiency of $p-n$ junction solar cells. J Appl Phys. 32, 510-519.

52. Stranks, S. D., Hoye, R.L.Z., Di, D.W., Friend, R.H. and Deschler, F. (2019). The Physics of Light Emission in Halide Perovskite Devices. Adv. Mater. 31, 1803336.

53. Kaji, H., Suzuki, H., Fukushima, T., Shizu, K., Suzuki, K., Kubo, S., Komino, T., Oiwa, H., Suzuki, F., Wakamiya, A., Murata, Y. and Adachi, C. (2015). Purely organic electroluminescent material realizing $100 \%$ conversion from electricity to light. Nat. commun. 6, 8476 .

54. Benduhn, J., Tvingstedt, K., Piersimoni, F., Ullbrich, S., Fan, Y.L, Tropiano, M., McGarry, Olaf Zeika, K.A., Riede, M.K., Douglas, C.J., Barlow, S., Marder, S.R., Neher, D., Spoltore, D. and Vandewal, K. (2017). Intrinsic non-radiative voltage losses in fullerene-based organic solar cells. Nat Energy. 2, 17053.

55. Vandewal, K., Albrecht, S., Hoke, E. T., Graham, K. R., Widmer, J., Douglas, J. D.,Schubert M., Materker W. R., Bloking J. T., Burkhard G. F., Sellinger A., Frechet J. M, Amassian A., Riede M. K., McGehee M. D., Neher D., Salleo A. (2014). Efficient charge generation by relaxed chargetransfer states at organic interfaces. Nature materials, 13, 63-68.

56. Qian, D., Zheng, Z., Yao, H., Tress, W., Hopper, T. R., Chen, S., Li, S., Liu, J., Chen, S., Zhang, J., Liu, X., Gao, B., Ouyang, L., Jin, Y., Pozina, G., Buyanova, I., Chen, W., Inganäs, O., Coropceanu, V., Bredas, J-L., Yan, H., Hou, J., Zhang, F., Bakulin, A. A., Gao, F. (2018). Design rules for minimizing voltage losses in high-efficiency organic solar cells. Nature materials, 17, 703-709.

57. Eisner, F.D., Azzouzi, M., Fei, Z.P., Hou, X.Y., Anthopoulos, T.D., Dennis, T.J.S., Heeney, M. and Nelson, J. (2019). Hybridization of Local Exciton and Charge-Transfer States Reduces Nonradiative Voltage Losses in Organic Solar Cells. J Am Chem Soc. 141, 6362-6374.

58. Azzouzi, M., Kirchartz, T. and Nelson, J. (2019). Factors Controlling Open-Circuit Voltage Losses in Organic Solar Cells. Trends in Chemistry. 1, 49-62.

59. Perdigon-Toro, L., Zhang, H.T., Markina, A., Yuan, J., Hosseini, S.M., Wolff, C.M., Zuo, G.Z., Stolterfoht, M., Zou, Y.P., Gao, F., Andrienko, D., Shoaee, S. and Neher, D.(2020). Barrierless Free Charge Generation in the High-Performance PM6:Y6 Bulk Heterojunction Non-Fullerene Solar Cell. Adv Mater. 32, e1906763.

60. Mo, D.Z., Chen, H., Zhou, J.D., Tang, N.N, Han, L., Zhu, Y.L., Chao, P.J., Lai, H.J., Xie, Z.Q. and He, F. (2020). Alkyl chain engineering of chlorinated acceptors for elevated solar conversion. J. Mater. Chem. A. 8, 8903-8912.

61. Zhu, L., Zhang, M., Zhou, G.Q., Hao, T.Y., Xu, J.Q., Wang, J., Qiu, C.Q., Prine, N., Ali, J., Feng, W., Gu, X.D., Ma, Z.F., Tang, Z., Zhu, H.M., Ying, L., Zhang, Y.M. and Liu, F. (2020). Efficient Organic Solar Cell with $16.88 \%$ Efficiency Enabled by Refined Acceptor Crystallization and Morphology with Improved Charge Transfer and Transport Properties. Adv Energy Mater. 18, 1904234. 
62. Feng, L.L., Yuan, J., Zhang, Z.Z., Peng, H.J., Zhang, Z.G., Xu, S.T., Liu, Y., Li, Y.F. and Zou, Y.P. (2017). Thieno[3,2-b]pyrrolo-Fused Pentacyclic Benzotriazole-Based Acceptor for Efficient Organic Photovoltaics. ACS Appl. Mater. Interfaces. 9, 31985-31992.

63. Liu, S., Yuan, J., Deng, W.Y., Luo, M., Xie, Y., Liang, Q.B., Zou, Y.P., He, Z.C., Wu, H.B. and Cao, $Y$. (2020). High-efficiency organic solar cells with low non-radiative recombination loss and low energetic disorder. Nat. Photonics. 5, 300 - 305.

64. Zhu, C., Yuan, J., Cai, F.F., Meng, L., Zhang, H.T., Chen, H.G., Li, J., Qiu, B.B., Peng, H.J., Chen, S.S., Hu, Y.B., Yang, C., Gao, F., Li, Y.F. and Zou, Y.P. (2020). Tuning the electron-deficient-core of non-fullerene acceptor to achieve over $17 \%$ efficiency in single-junction organic solar cell. Energy Environ. Sci. DOI: 10.1039/DOEE00862A.

65. Blouin, N., Michaud, A., Gendron, D., Wakim, S., Blair, E., Neagu-Plesu, R., Belletete, M., Durocher, G., Tao, Y., and Leclerc, M. (2008). Toward a rational design of poly (2, 7-carbazole) derivatives for solar cells. Journal of the American Chemical Society, 130, 732-742.

66. Zhou, Z., Liu, W., Zhou, G., Zhang, M., Qian, D., Zhang, J., Chen, S., Xu, S., Yang, C., Gao, F., Zhu, H., Liu, F., and Zhu, H. (2020). Subtle molecular tailoring induces significant morphology optimization enabling over $16 \%$ efficiency organic solar cells with efficient charge generation. Advanced materials, 32, 1906324.

67. Zhou, J., Zhang, W., Jiang, X.F., Wang, C., Zhou, X., Xu, B., Liu, L.L., Xie, Z.Q. and Ma, Y. (2018). Magic-Angle Stacking and Strong Intermolecular pi-pi Interaction in a Perylene Bisimide Crystal: An Approach for Efficient Near-Infrared (NIR) Emission and High Electron Mobility. J. Phys. Chem. Lett. 9, 596-600.

68. Tiedje, T. (1982). Band tail recombination limit to the output voltage of amorphous silicon solar cells. Appl Phys Lett. 40, 627-629.

69. Heumueller, T., Burke, T. M., Mateker, W. R., Sachs-Quintana, I. T., Vandewal, K., Brabec, C. J. and McGehee, M. D. (2015). Disorder-Induced Open-Circuit Voltage Losses in Organic Solar Cells During Photoinduced Burn-In. Adv Energy Mater. 5, 1500111.

70. Menke, S. M., Cheminal, A., Conaghan, P., Ran, N. A., Greehnam, N. C., Bazan, G. C., Nguyen, T.Q., Rao, A., Friend, R. H. (2018). Order enables efficient electron-hole separation at an organic heterojunction with a small energy loss. Nat. commun. 9, 1-7.

71. Garcia-Belmonte, G. (2010). Open-circuit voltage limit caused by recombination through tail states in bulk heterojunction polymer-fullerene solar cells. Appl Phys Lett. 96, 113301.

72. Vandewal, K., Tvingstedt, K., Gadisa, A., Inganäs, O., \& Manca, J. V. (2010). Relating the opencircuit voltage to interface molecular properties of donor:acceptor bulk heterojunction solar cells. Phys Rev B. 81, 125204.

73. Yuan, J., Zhang, C.J, Chen, H.G., Zhu, C., Cheung, S.H., Qiu, B.B., Cai, F.F., Wei, Q.Y., Liu, W., Yin, H., Zhang, R., Zhang, J.D, Liu, Y., Zhang, H.T., Liu, W.F., Peng, H.J., Yang, J.L., Meng, L., Gao, F., So, S.K., Li, Y.F. and Zou, Y.P. (2020) Understanding Energetic Disorder in ElectronDeficient-Core-Based Non-fullerene Solar Cells. Sci. China. Chem. 63, 1159-1168.

74. Zhang, C.J, Yuan, J., Chiu, C. L., Yin, H., Liu, W.F., Zheng, G.H.J, Ho, J.K.W.H, Su, Z.H., Gao, X.Y., Gao, F., Zou, Y.P., and So, S.K. (2020). A disorder-free conformation boosts phonon and charge transfer in an electron-deficient-core-based non-fullerene acceptor. Journal of Materials Chemistry A, 8, 8566-8574.

75. Ran, N. A., Roland, S., Love, J. A., Savikhin, V., Takacs, C. J., Fu, Y.T., Li , H., Coropceanu, V., Liu, X.F., Brédas, J-L., Bazan, G.C., Toney, M.F., Neher, D. and Nguyen, T.-Q (2017). Impact of interfacial molecular orientation on radiative recombination and charge generation efficiency. Nat. Commun. 8, 79.

76. Tress W. (2014) "Organic solar cells." Organic Solar Cells. Springer, Cham, 67-214.

77. Yu, R., Yao, H., Cui, Y., Hong, L., He, C., and Hou, J. (2019). Improved Charge Transport and Reduced Nonradiative Energy Loss Enable Over 16\% Efficiency in Ternary Polymer Solar Cells. Adv. Mater. 2019, 1902302. 
78. Qin, Y., Zhang, S., Xu, Y., Ye, L., Wu, Y., Kong, J., Xu, B.W., Yao, H.F., Ade, H.and Hou, J. (2019). Reduced Nonradiative Energy Loss Caused by Aggregation of Nonfullerene Acceptor in Organic Solar Cells. Adv Energy Mater. 9, 1901823.

79. Abbaszadeh, D., Kunz, A., Wetzelaer, G. A. H., Michels, J. J., Crăciun, N. I., Koynov, K., Lieberwirth, I. and Blom, P. W. M. (2016). Elimination of charge carrier trapping in diluted semiconductors. Nat Mater. 15, 628-633.

80. Rao, A., Chow, P. C. Y., Gélinas, S., Schlenker, C. W., Li, C.Z., Yip, H.L., Jen, A.K.Y, Ginger, D.S. and Friend, R. H. (2013). The role of spin in the kinetic control of recombination in organic photovoltaics. Nature. 500, 435-439.

81. Menke, S. M., Sadhanala, A., Nikolka, M., Ran, N. A., Ravva, M. K., Abdel-Azeim, S., Stern, H.L., Wang, M., Sirringhaus, H., Nguyen, T.Q., Brédas, J.L., Bazan, G.C. and Friend, R. H. (2016). Limits for Recombination in a Low Energy Loss Organic Heterojunction. ACS nano. 10, 1073610744.

82. Chow, P.C., Gelinas, S., Rao, A. and Friend, R.H. (2014). Quantitative bimolecular recombination in organic photovoltaics through triplet exciton formation. J Am Chem Soc. 136, 3424-3429.

83. Mathieu, M., Leclerc, M. (2020). Rcent Progress on Indoor Organic Photovoltaics: From Molecular Design to Production Scale. ACS Energy Lett. 5, 1186-1197.

84. Hwa, S.R., Song Y.P., ,Tack H.L., Jin Y.K. and Han, Y.W. (2020). Rcent Progress in Indoor Organic Photovoltaics. Nanoscale, 12, 5792. 